\title{
Un centro de interpretación para el uso social del patrimonio histórico de la Universidad Nacional Mayor de San Marcos
}

Apuntes de Investigación

Recibido: 21/09/2020

Aprobado: 20/10/2020

Publicado: 05/02/2021

\author{
Ricardo Pinto-Bazurco Mendoza \\ Universidad Nacional Mayor de San Marcos \\ rpintobazurcom@unmsm.edu.pe
}

\begin{abstract}
RESUMEN
Desde la perspectiva de la gestión del patrimonio cultural se plantea el diseńo de un espacio que permita conocer, a todo el público, el patrimonio histórico de la Universidad Nacional Mayor de San Marcos. Pues resulta paradójico que la exposición de sus bienes con valor patrimonial, circunscritos a su rica y vasta historia, sea un ámbito casi desconocido por carecer de un espacio físico y/o virtual adecuado, ordenado y organizado para su permanente exhibición. Este patrimonio, en su conjunto, es percibido como objetos lejanos y aislados o, simplemente, desconocidos debido a la falta de una adecuada promoción y divulgación de la importante participación de la institución académica en el proceso de desarrollo de la historia cultural y nacional del Perú. En tal sentido, es posible plantear un nuevo escenario a través del diseńo y desarrollo de un centro de interpretación que promueva el uso social del patrimonio histórico de la UNMSM donde los receptores puedan descubrir, de forma didáctica y tangible, el significado histórico y el valor patrimonial de los bienes culturales que posee la Universidad Decana de América.
\end{abstract}

Palabras Clave: patrimonio histórico; interpretación; uso social; gestión del patrimonio cultural; UNMSM; Perú.

\section{An interpretation center for the social use of the historical heritage of the University of the Universidad Nacional Mayor de San Marcos}

\begin{abstract}
From the perspective of the management of cultural heritage, the design of a space that allows the public to know the historical heritage of the National University of San Marcos is proposed. Well, it is paradoxical that the exhibition of its assets with patrimonial value, circumscribed to its rich and vast history, is an almost unknown area because it lacks an adequate physical and / or virtual space, ordered and organized for its permanent display. This heritage, as a whole, is perceived as distant and isolated objects or, simply unknown due to the lack of adequate promotion and dissemination of the important participation of the academic institution in the process of development of the cultural and national history of Peru.

In this sense, it is possible to propose a new scenario through the design and development of an interpretation center that promotes the social use of the historical heritage of the UNMSM where the recipients can discover, in a didactic and tangible way, the historical meaning and heritage value of the cultural assets owned by the Dean University of America.
\end{abstract}

KeYwords: Historical heritage; Interpretation; Social Use; Cultural Heritage Management; UNMSM, The University of San Marcos; Peru. 


\section{Introducción}

$\mathbf{N}$ o cabe duda alguna de la trascendencia e importancia que reviste el papel que ha desarrollado la Universidad Nacional Mayor de San Marcos ${ }^{1}$, tanto como institución y como alma mater de profesionales, en las diferentes páginas que conforman la propia Historia del Perú y de América. Empero, siendo la universidad "más antigua del Nuevo-Mundo" (Unanue [1793] 1985: 218), resulta paradójico que el estudio y promoción de su historia sea una materia relegada en la producción historiográfica contemporánea circunscrita solo a algunos especialistas, quienes han seguido el derrotero marcado por entrańables eruditos en el tema. Asimismo, no se concibió un proyecto concreto para el desarrollo de un espacio dedicado exclusivamente a la conservación, exposición y divulgación del patrimonio histórico de la universidad sanmarquina, limitándose solo a propuestas ambiguas que se fueron diluyendo con el tiempo.

En tal sentido, desde la perspectiva de la gestión del patrimonio cultural se advierte la ausencia de un espacio físico y/o virtual adecuado que permita la exposición especializada, ordenada y organizada de los bienes culturales pertenecientes al patrimonio histórico de la UNMSM. Carencia que no permite comprender, fomentar y promover el conocimiento tangible de la rica y vasta historia de la universidad sanmarquina, así como su importancia en el proceso de desarrollo de la historia cultural y nacional del Perú, cuyo impacto no se debe soslayar, pues también se irradia sobre el resto del continente. Este aspecto negativo ha generado un paulatino menoscabo en la tarea por salvaguardar y conservar el mencionado patrimonio histórico, del cual resulta imposible develar su real importancia y trascendencia en tanto su significado histórico y valor patrimonial se mantenga aislado. Hecho que, además, trae como consecuencia la poca identificación y sentido de pertenencia de las nuevas generaciones de sanmarquinos y ciudadanos con el legado histórico-cultural de la primera institución universitaria de América. Como ejemplo del desconocimiento generalizado es posible mencionar lo sucedido en la exposición "Plata de los Andes. Tesoros del Perú”, organizado por el Museo de Arte

1 En adelante se referirá por sus respectivas siglas: UNMSM. de Lima (MALI) en el año 2019, en la cual se exhibieron algunos bienes históricos culturales sanmarquinos como las ánforas usadas en los exámenes (s. XVII), una ampolla (reloj de arena, s. XVII) y una campanilla de plata de 12 onzas la cual fue enviada por el rey Carlos $\mathrm{V}$ como obsequio a la recién fundada Universidad de la Ciudad de los Reyes en 1551. En dicha exposición, las cartillas informativas contuvieron errores de fechado y apuntes históricos inexactos que desinformaban a los receptores. Estas fallas, presumiblemente, tuvieron su origen en los responsables de catalogar las piezas en la misma universidad, así como los propios curadores de la mencionada exposición. Esto demuestra las falencias que se producen ante la ausencia de un ente responsable y especializado, asimismo, esta problemática limita a la UNMSM como espacio natural para la promoción y divulgación de su propia historia cultural e institucional al no ofrecer una experiencia integral; desaprovechando, así, la estratégica ubicación que ofrece, por citar un ejemplo, el Centro Cultural de la UNMSM circunscrito al Centro Histórico de Lima.

\section{En busca de antecedentes y experiencias}

Al escudriñar la existencia de casos particulares que puedan prever información relacionada a la propuesta a plantearse, es posible corroborar que no existe en el país una propuesta funcional, desde el punto de vista de la gestión patrimonial, de un centro de interpretación dedicado exclusivamente a la historia universitaria en su conjunto. Es decir, como una unidad integral constituyente, física y/o virtual, en la que se conjuguen la promoción, salvaguarda y conservación del patrimonio histórico con la función didáctica-interpretativa y su uso social. A pesar de las carencias de casos existentes en el Perú es posible mencionar el espacio virtual desarrollado por la Universidad Nacional de Ingeniería llamado "Centro de Historia UNI" que, a modo de catálogo, sólo ofrece bibliografía y algunos documentos que han sido digitalizados y puestos en línea como herramienta para los investigadores. Lo mismo sucede con el repositorio del Instituto Riva-Agüero de la Pontificia Universidad Católica del Perú y, recientemente, el Fondo Editorial de la UNMSM ha colgado en la red bibliografía relacionada a su historia. 
Sin embargo, estas propuestas no comprenden un espacio que permita dinamizar una experiencia vivencial que involucre al visitante con la información ofrecida.

En el ámbito internacional, por otro lado, es posible encontrar algunos espacios con el funcionamiento integral que se pretende como es el caso del Museo de Historia Universitaria "José María Morelos y Pavón" de la Universidad Autónoma del Estado de México que cuenta con "7 salas de exposición grafica permanente, módulos interactivos, videos, pantallas de toque y una línea del tiempo digital que se actualiza constantemente" según su propia descripción. Otro ejemplo son las muestras temporales que ofrece la Universidad de Salamanca de España donde el Grupo de Investigación Reconocido (GIR) "Historia Cultural y Universidades Alfonso IX" (CUNALIX) desarrolla diferentes temáticas expuestas al público.

En suma, experiencias que resultan escasas y lejanas, pero referenciales para el caso que se plantea en concreto, pues los centros de interpretación son utilizados para otras temáticas como es el caso del desarrollado por la Municipalidad Metropolitana de Lima con el Programa Municipal para la Recuperación del Centro Histórico de Lima (MML-PROLIMA 2017: 127). Habría que añadir los útiles planteamientos estratégicos del Museo Nacional ThyssenBornemisza (Thyssen-Bornemisza 2019) y los del Instituto Andaluz del Patrimonio Histórico ambos de Espańa, además, la propuesta de virtualidad del patrimonio según el modelo expuesto por el Museo Colonial de Bogotá (Colombia) a través de la muestra "Simulacros de Poder" del 2020.

\section{Historia, patrimonio y gestión}

De esta manera, y ante las experiencias expuestas, es pertinente diseñar un centro de interpretación o equipamiento cultural dinámico para la UNMSM como espacio físico y virtual, donde la comunidad sanmarquina y la generalidad puedan conocer, en forma didáctica y tangible, la vasta historia de la UNMSM a través del uso social de su patrimonio histórico. De esta manera, el receptor puede aprender y revelar la trascendencia del valor patrimonial de los bienes culturales expuestos y, con ello, desarrollar un mayor sentido de pertenencia, percepción positiva y compromiso por salvaguardar y conservar el legado cultural e institucional que posee la Universidad Decana de América.

Por ello, antes de plantear una propuesta, cabe tener presente que la historia de la UNMSM es más que profusa. Fundada hace más de cuatro centurias, ilustres personajes se encargaron de escribir apuntes y amplios tratados sobre su trascendencia histórica que datan desde los primeros ańos de su largo derrotero.

Hechos que fueron analizados y publicados por eruditos desde el siglo XVII como Cobo, Calancha (1660) y León Pinelo (1648); en el Siglo de las Luces aparece Baquíjano (1791) para pasar al periodo decimonónico, donde brillaron Fuentes (1866) y Dávila Condemarín (1854), hasta llegar al siglo XX con las abundantes y prolijas publicaciones de Luis Antonio Eguiguren, consagrado al estudio de su evolución intelectual con su profusa producción de importantes aportes heurísticos, al igual que Daniel Valcárcel, especializado su desenvolvimiento durante la época del antiguo régimen, Peña (1938), Villarán (1938), Porras (1951), Ella Dunbar Temple (1974), Miguel Maticorena, entre otros. Quienes analizaron la participación activa de la Universidad en los distintos episodios de la historia nacional como, por citar unos ejemplos, la gesta emancipadora y la formación de los principales ideólogos y precursores de la causa de la patria libre, como José Baquíjano y Carrillo, Vicente Morales Duárez, Toribio Rodríguez de Mendoza, Vidaurre y un sinfín de patriotas. Asimismo, el haber suscrito y reconocido, en 1821, la Independencia del Perú, además de brindar su vieja sede central para la instalación de la Asamblea Constituyente de 1822, convocada por el Protector José de San Martín. También participó en la defensa de la patria ante los ataques españoles, que pretendían recuperar sus antiguas posesiones coloniales, y cuyo principal héroe fue el sanmarquino José Gálvez, caído en el combate del 2 de mayo de 1866. Tampoco fue ajena a la infausta guerra con Chile, en la cual se vio afectada al perder importantes bienes (libros y laboratorios), así como la vida de muchos valerosos sanmarquinos en las distintas batallas (Pinto-Bazurco 2019).

En suma, grandes esfuerzos por registrar la importancia y valor histórico de una institución cuya trascendencia es irrefutable sin ninguna duda, pero cuya promoción, paradójicamente, no encuentra 
el espacio de difusión que merece desde su propia matriz.

Con relación a ello, la gestión del patrimonio cultural se convierte en el agente catalizador que permite dinamizar el conocimiento y aprendizaje de la Historia de la UNMSM a través de la exposición permanente, física y/o virtual, de su patrimonio histórico (Ballart, 2002), que a su vez promueve la valoración y reforzamiento del criterio de representación o sistema de representación que la comunidad sanmarquina asimila de su ámbito cultural y de "una eventual proyección de sí mismo", como lo deja entender de Vovelle (2003: 18). Asimismo, para comprender dicha interpretación resulta necesario tomar en cuenta otros aspectos teóricos para referirse al "valor de los bienes del patrimonio histórico" (Ballart, Fullola \& Petit, 1996: 216), los cuales se condensan en tres útiles acepciones: "Valor de uso, Valor formal y Valor simbólico/comunicativo" (1996). De lo cual es posible colegir tres criterios como base para el diseño que se propone: Valor Documental, Valor Testimonial y Valor Artístico.

En otro orden de ideas, resulta importante sumar el concepto de tradición, que busca sentar una automática continuidad con el pasado, a decir de Hobsbawm \& Terence (2003: 3). Elemento fundamental junto a las dinámicas de la cultural, como lo sostiene García Canclini (1999), con la finalidad de comprender el sistema de apreciación que surge en consecuencia de la representación, la cual no hace más que ordenarla mediante la observación.

La referida base conceptual sirve como respaldo para diseñar un centro de interpretación del patrimonio histórico para la UNMSM, entendido como un espacio físico y/o virtual cuya función permite investigar, conservar, divulgar y poner en uso social el rico legado cultural sanmarquino. Plataforma donde se pueda procesar la información brindada para un correcto aprendizaje (Martín 2009: 50) y comprensión, de forma didáctica y tangible, del legado histórico material de la UNMSM (Ballart 2002: 51). A la vez que se convierta en agente catalizador de la propia historia nacional, logre incentivar otros factores que converjan con la promoción del desarrollo social e individual, donde la cultura sea una herramienta y un elemento de prestigio que promueva la justicia, equidad, solidaridad y sea un pilar de sostenibilidad (Thyssen-Bornemisza 2019: 16).
Del mismo modo, esta iniciativa fomenta la promoción del desarrollo a través del turismo integrado a los circuitos culturales de la ciudad, que contará con la participación activa de profesionales formados en la misma casa de estudios donde el cuidado y conservación del patrimonio resulta fundamental.

\section{Una experiencia práctica}

Con la finalidad de demostrar la viabilidad de una propuesta de gestión para el diseño de un centro de interpretación para el uso social del patrimonio histórico, se planteó la organización y producción de una muestra expositiva en el marco de las actividades conmemorativas por el aniversario de su fundación.

La propuesta se expuso ante la Oficina General de Imagen Institucional de la UNMSM y luego ante la Comisión ${ }^{2}$ de Celebraciones Conmemorativas del $467^{\circ}$ Aniversario de fundación de la UNMSM (UNMSM, Resolución Rectoral No 00598-R18, 12 de febrero del 2018), presidida por el Dr. José Manuel Yampufé, responsable de la Dirección General de Responsabilidad Social de la UNMSM. La referida gestión dio como resultado la aprobación, por la mencionada Comisión, de la muestra intitula "Academia Limensi: San Marcos en su historia", compuesta por diferentes y variadas piezas del Acervo Pinto-Bazurco (colección privada), cuyo nutrido catálogo contiene más de un centenar de objetos históricos. Estos están compuestos por libros, libros de texto, tesis, documentos de varios tipos, diplomas, fotografías, medallas, monedas conmemorativas, reproducciones de grabados, usos estudiantiles, etc., que fueron expuestos durante abril y mayo del 2018 en la sede del Centro Cultural de la $\mathrm{UNMSM}^{3}$, ubicado en el Centro Histórico de Lima (PROLIMA, Mapa Centro Histórico de Lima, 2016), espacio declarado "Patrimonio Cultural de la Humanidad" (Fujita, Fabbri, Sánchez \& et al. 2011: 318).

Luego de oficializar el préstamo de los bienes, mediante una carta presentada (fechada el 14 de abril

2 Este grupo de trabajo se encargó de la organización de todos los eventos oficiales que se realizaron durante las celebraciones de aniversario, asimismo, dispuso de reconocimientos a sanmarquinos ilustres alrededor del mundo.

3 Fue creado mediante Resolución Rectoral, siendo Rector el Dr. Wilson Reátegui Chávez, el 19 de septiembre de 1995. En adelante se referirá por sus respectivas siglas: CCSM. 
del 2018) al director del CCSM, Ing. César Franco, se inició la respectiva instalación de la muestra. Su preparación tomó una semana en uno de los ambientes que se ubican en torno al emblemático "Patio Principal o de Maestros" (Agustín 2005: 84) conocido, actualmente, como "Patio de Derecho" de "La Casona” como también se denomina al CCSM.

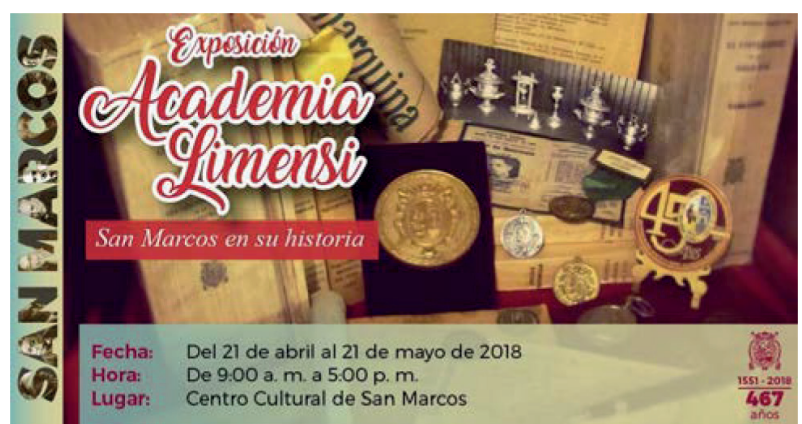

Afiche y publicidad oficial de la muestra (Diseño: OGII-UNMSM 2018.
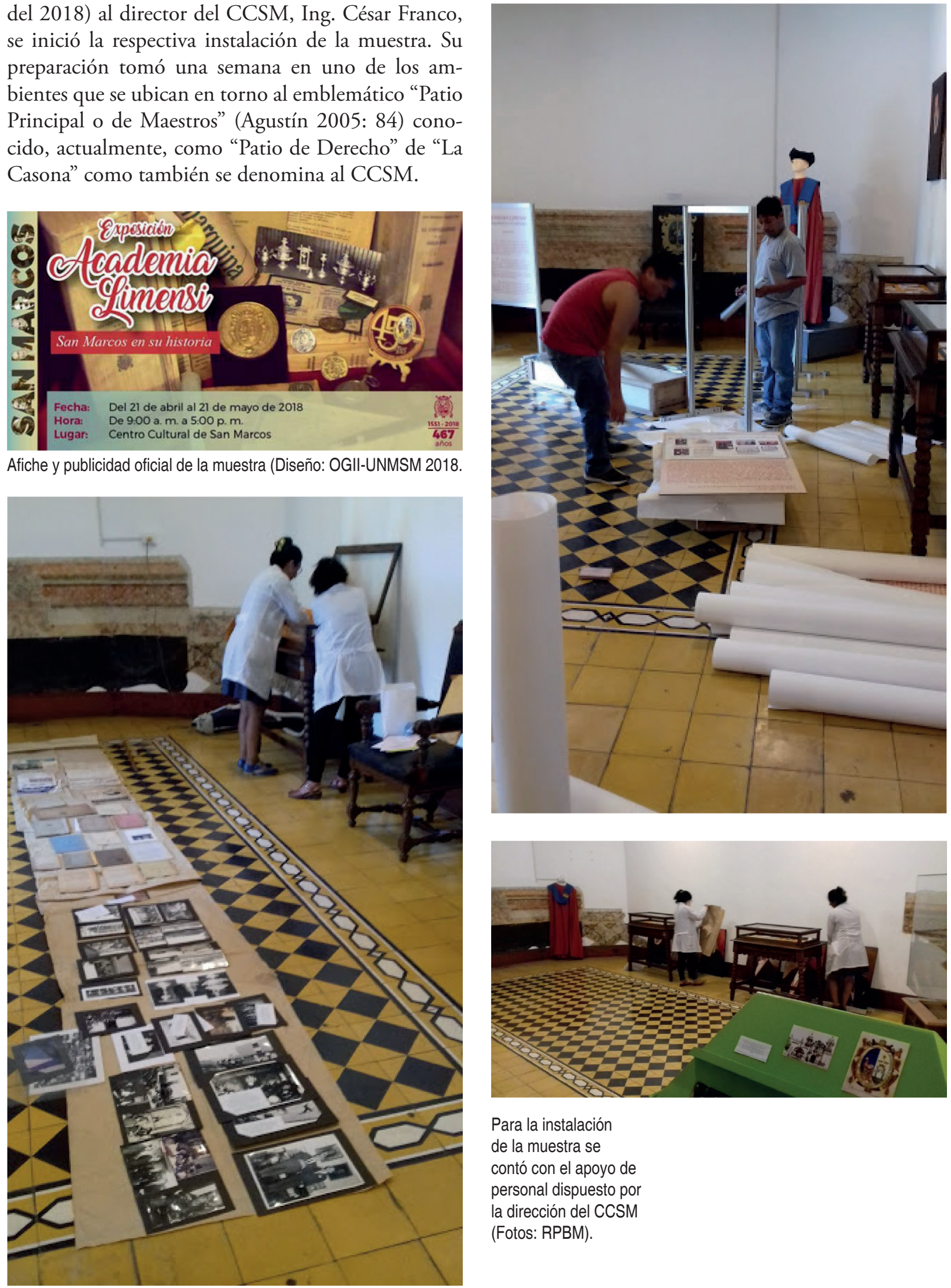

Para la instalación

de la muestra se

contó con el apoyo de

personal dispuesto por

la dirección del CCSM

(Fotos: RPBM). 

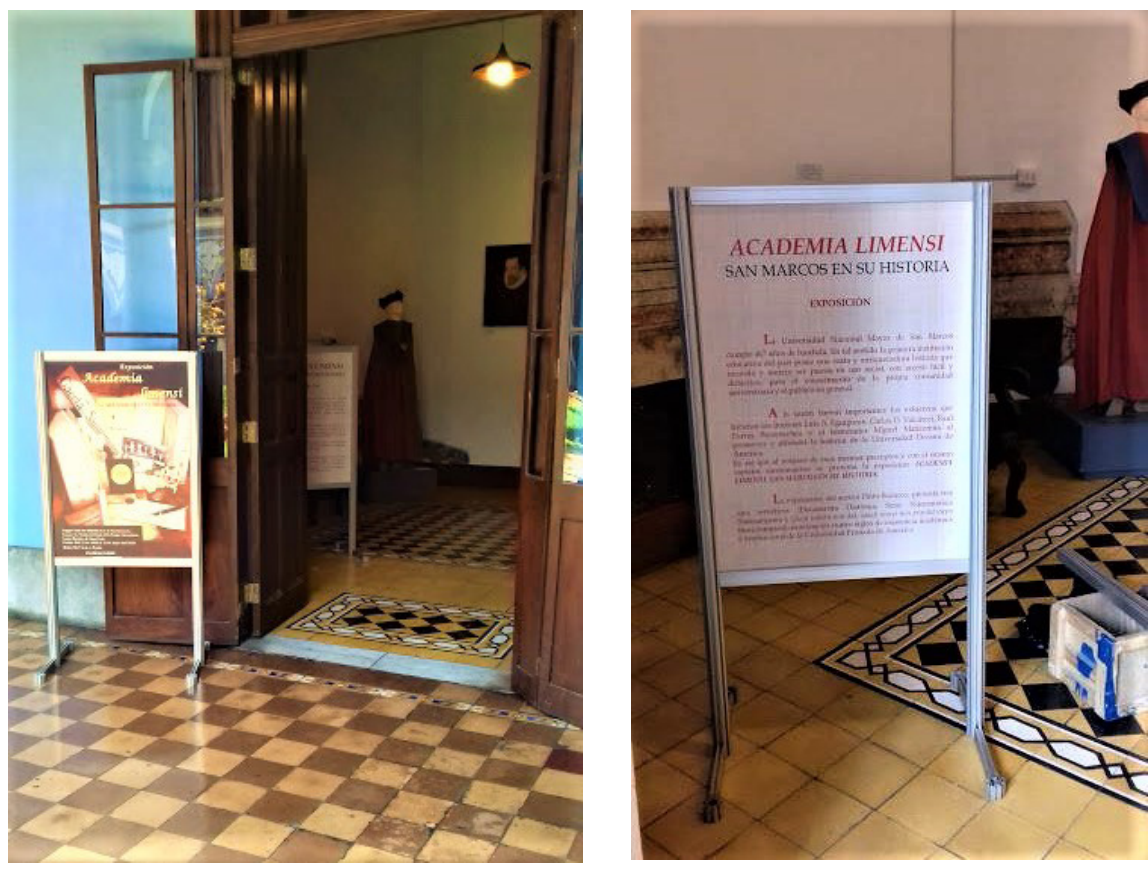

Paneles

informativos

(Fotos:

RPBM).

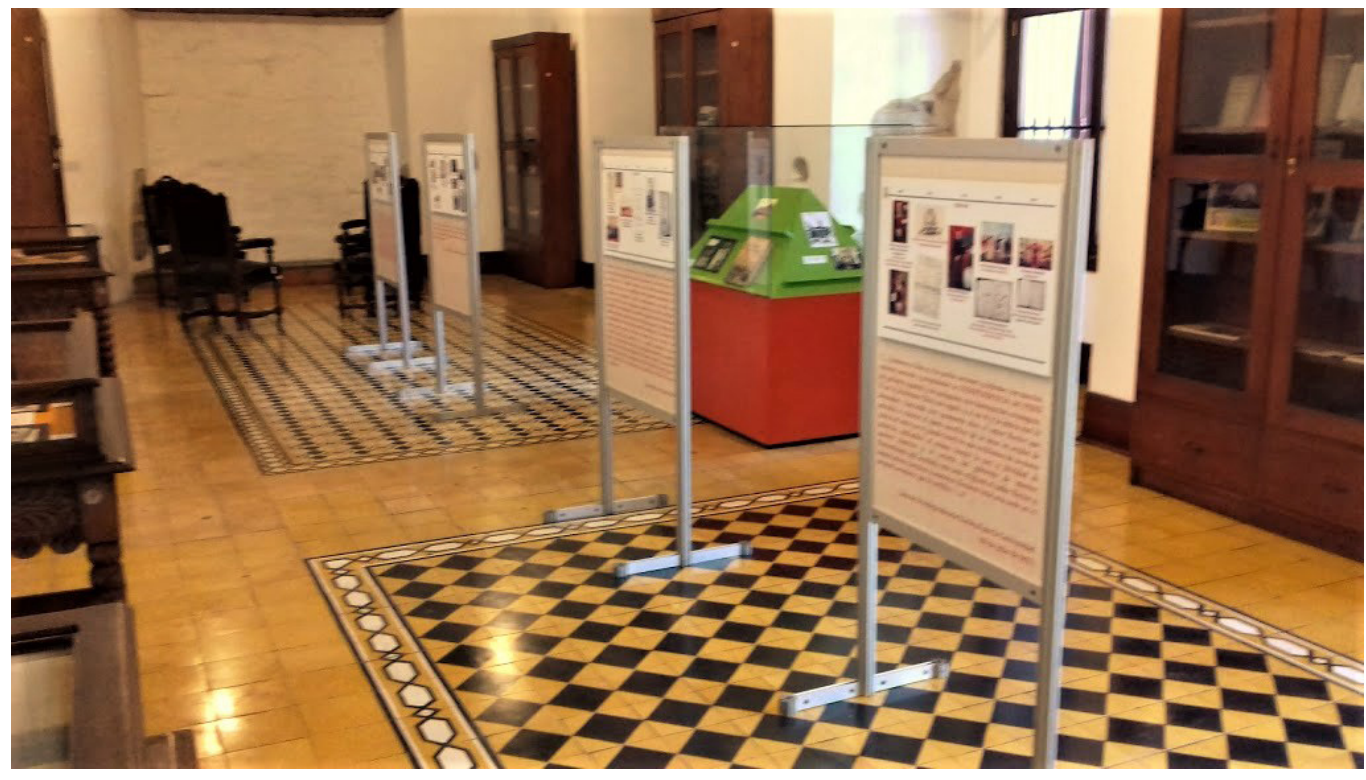

La información ofrecida en los diez paneles, distribuidos en la sala, sirvió de apoyo y guía al receptor de la información. (Fotos: RPBM).

El diseño y guión de la muestra estuvo basado en una investigación de riguroso escrutinio que ofreció a los visitantes información concisa, expresada en un leguaje claro y llano, que reveló su interés por conocer el significado de las diferentes dinámicas y hechos que constituyen la larga historia académica e institucional de la UNMSM.

La muestra fue dividida en tres ejes temáticos ("Documenta histórica", "Serie numismática" y "Miscelánea sanmarquina”) para contextualizar mejor, en tiempo y espacio, el recorrido histórico de los receptores. A modo de orientación (Bertonatti 2009), en la sala de exposición, se incluyó una sintética y didáctica línea de tiempo repartida en diez paneles ${ }^{4}$ móviles que mostraban hechos emblemáticos acaecidos desde 1548 hasta el año 2000, y que a su vez se enmarcaron en los diferentes periodos de nuestra historia nacional (colonia, emancipación, guerra con Chile, etc.); además, se destacó la

4 Cuyas proporciones fueron de $1 \mathrm{~m} \times 0.70 \mathrm{~cm}$, usado en imágenes, y elevado a una altura de $1.50 \mathrm{~m}$. sobre el piso. 


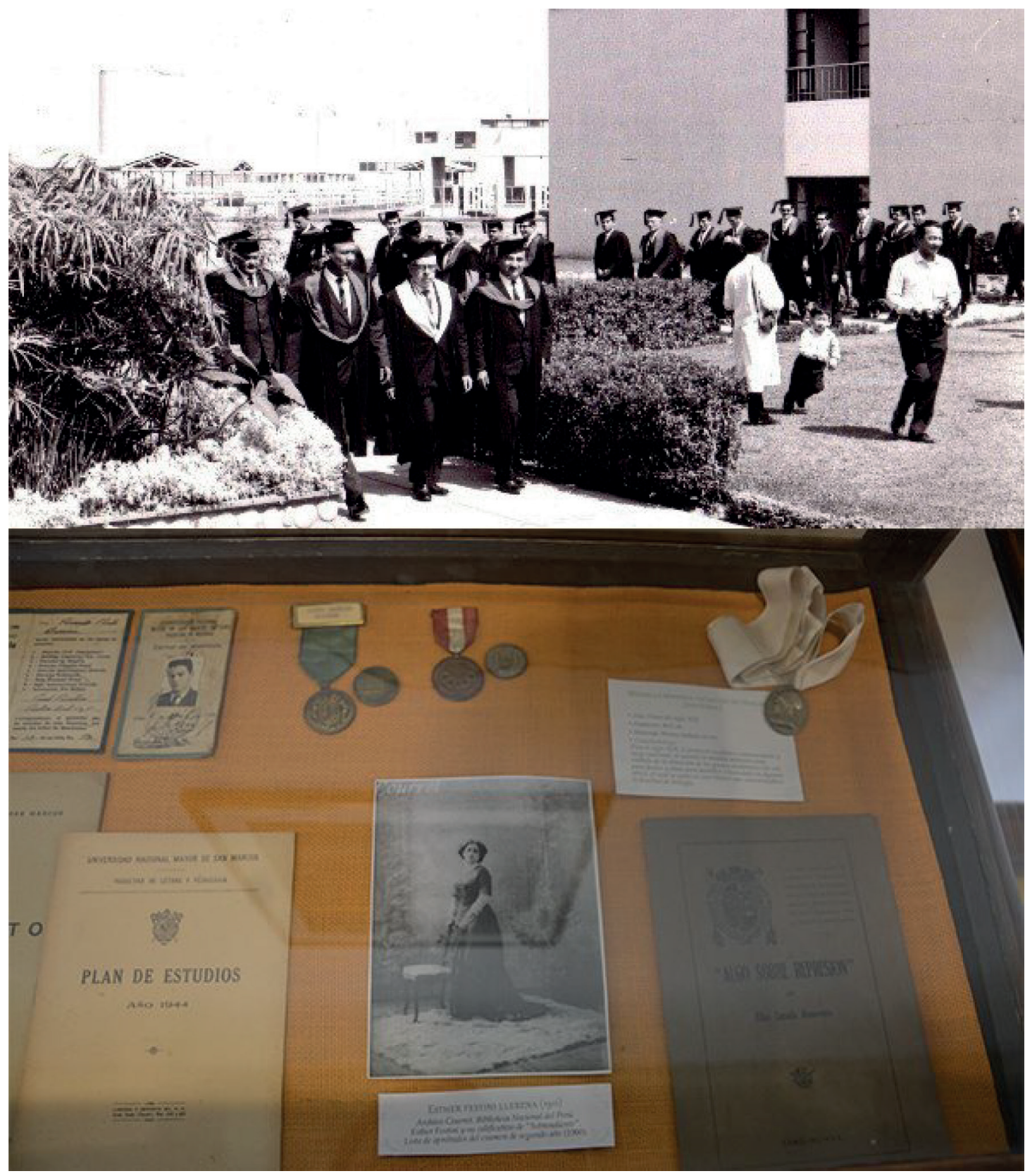

Una de las vitrinas con algunos bienes exhibidos (Foto: Boletín San Marcos al Día 2018).

participación de múltiples personajes ilustres como Fray Tomás de San Martín, Diego y Antonio León Pinello, José Baquíjano (de quien se replicó su respectivo traje académico compuesto por una loba o traje talar, una beca cerúlea con corona dorada y un bonete de cuatro puntas), Esther Festini, Raúl Porras, Jorge Basadre, Ella Dunbar Temple, Mario Vargas Llosa, entre otros, y el proceso de desarrollo del pensamiento crítico-científico en las Letras y las Ciencias emanado de las aulas sanmarquinas.
Todo ello se complementó, eficientemente, con los objetos históricos presentados pertenecientes al nutrido catálogo del Acervo Pinto-Bazurco, material que ha sido expuesto en sendas muestras los años 2015 (solo la Serie Numismática como parte de una exposición conjunta con el Archivo Histórico Domingo Angulo de la UNMSM, realizada en la Biblioteca Central de la UNMSM), 2016, 2017 (muestra completa en el Instituto Raúl Porras Barrenechea. Centro de Altos Estudios y de Investigaciones Peruanas de la UNMSM) y 2018 (Centro Cultural de la UNMSM), 
y la inclusión de algunos bienes culturales cedidos por el CCSM, que comprendieron solo siete pequeñas reproducciones de cuadros y mueblería.

Los objetos históricos fueron distribuidos en diferentes vitrinas ubicadas a lo largo de la sala según el eje temático correspondiente, los cuales contaron con su respectiva cartela de referencia y un código $\mathrm{QR}^{5}$, como el que se muestra en la imagen, que incluía una sucinta y precisa cartilla de

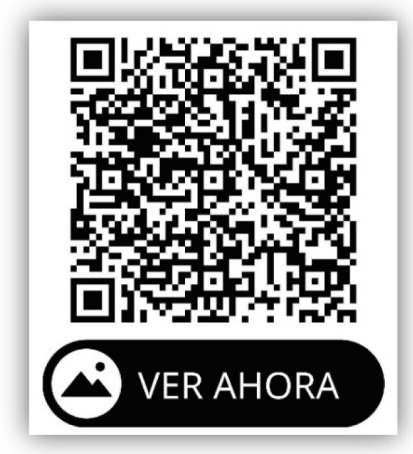
descripción que contribuyó a un eficiente uso social de la información brindada por parte de los visitantes.

\section{Resultados preliminares de la experiencia práctica}

En un primer balance general, la muestra, que estuvo abierta durante un mes y fue de libre acceso, resultó satisfactoria. Esto en virtud a la asistencia numerosa de visitantes propios y extraños al fuero sanmarquino, asimismo, la afluencia de turistas que visitaron el CCSM como parte del circuito que ofrece el Centro Histórico de Lima. Pues resulta insoslayable revelar al público el significado de la participación de los cuerpos literarios en la formación de la cultura nacional, hecho que reviste suma importancia "ya que la UNMSM es la primera y más importante institución educativa del país, poseedora de una vasta historia, que merece ser difundida entre la comunidad universitaria y público en general" (UNMSM, Exposición "Academia Limensis», Mayo 2017).

Por otro lado, se evidenciaron algunos aspectos que deben ser mejorados en relación con la logística usada en la sala de exposiciones, ofrecida por el CCSM, como el limitado e inadecuado equipamiento (vitrinas) para el uso expositivo y la carencia de equipo multimedia que impidió la proyección de

5 Siglas para Quick Response code ("código de respuesta rápida»). Para acceder a la información contenida en el código publicado en este artículo es necesario contar, en su teléfono inteligente, con una aplicación que sirva como escáner QR. Dicha aplicación es posible descargarla de forma gratuita en las diferentes plataformas virtuales. medios audiovisuales que conformaban el catálogo expuesto.

\section{A modo de conclusión}

Implementar un centro de interpretación o equipamiento cultural dinámico cubre la carencia y necesidad que posee la UNMSM de conocer y salvaguardar su legado histórico-cultural, el cual es posible observar desde una "perspectiva global e integradora" (Bertonati Iriani \& Castelli 2010: 25). De esta manera, el centro de interpretación permite a los visitantes, comunidad sanmarquina y público en general, tener una experiencia cercana, cómoda, clara y tangible con el pasado de una institución cuyo papel ha sido fundamental para el desarrollo de la cultura peruana.

En tal sentido, investigar, conservar, divulgar y poner en uso social el conocimiento que reviste el interés patrimonial que emana de la UNMSM permite que el sistema de apreciación, determinado por las modalidades de observación del entorno y del mismo del individuo o grupo social, fortalezca los vínculos afectivos del fuero universitario sanmarquino y la generalidad con la institución utilizando su propia historia, representada en su patrimonio histórico como medio de cohesión. Esto logrado a través del novedoso enfoque del "aprendizaje informal" (ThyssenBornemisza 2019:.25), que concede una mejor experiencia donde la "sorpresa, asombro y emoción" (Thyssen-Bornemisza 2019: 25) despiertan el interés por conocer el patrimonio cultural sanmarquino.

Por otro lado, la selección y reunión del patrimonio histórico, original y/o reproducción, que forma parte de la sala de exposición permanente (física y/o virtual), se rige bajo el criterio de un guión coherente que sintetiza y representa los hechos, personajes y reminiscencias más relevantes de la vasta historia sanmarquina, elemento que comunica al visitante el "mensaje en torno a la valoración y conservación del patrimonio" (Bertonatti, Iriani \& Castelli 2010: 21), expuesto lo cual se potencia con el entorno que conforma, por ejemplo, el complejo del CCSM, que posee una excelente arquitectura, como sus patios, murales, techumbre (Mariátegui 1951) y contexto ideal para los fines que se pretenden.

Así, este espacio conjuga la experiencia moderna que ofrece el aprendizaje informal, que se apoya en 


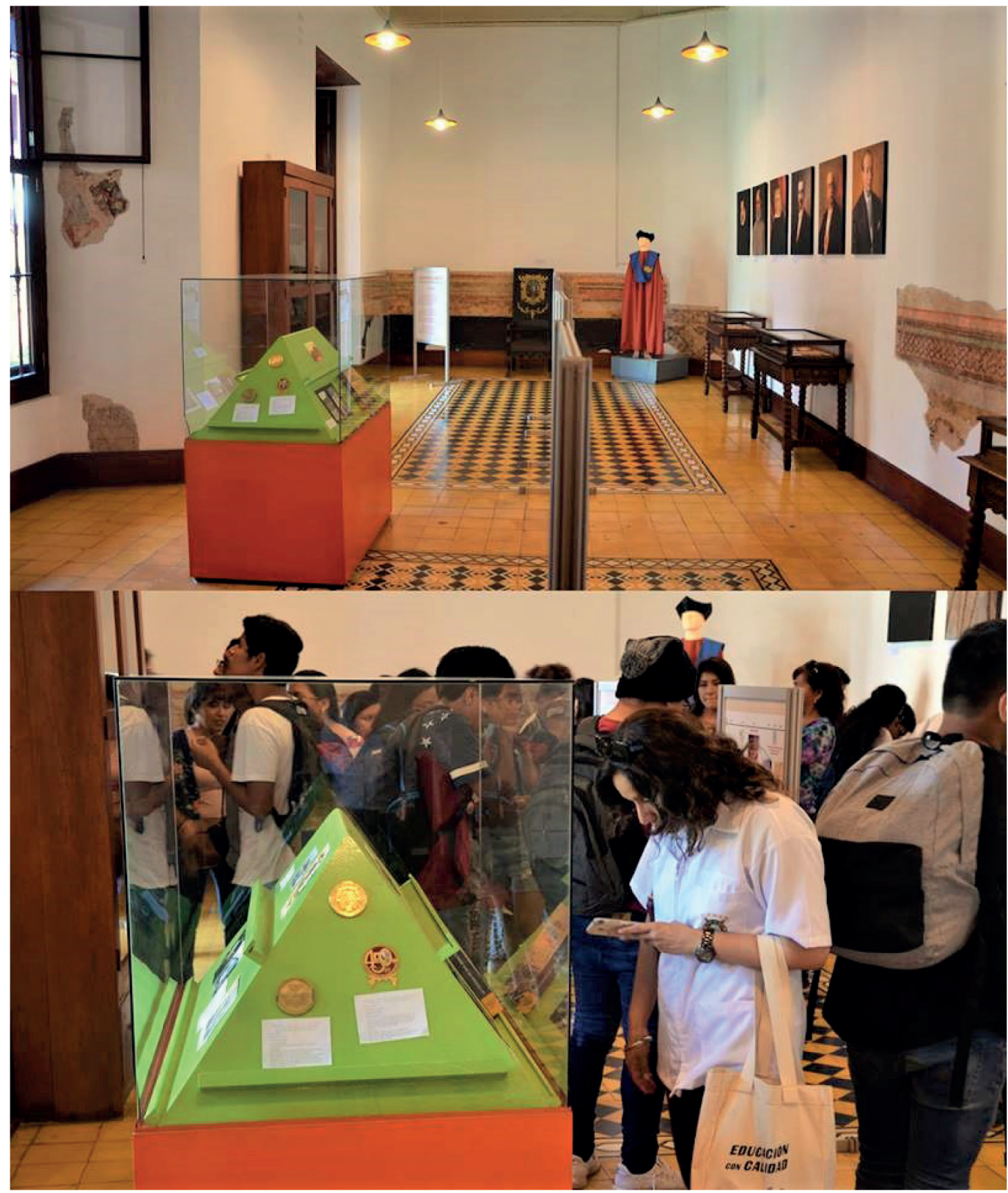

La muestra,

antes y durante, el día de su inauguración (Foto: SDMUNMSM 2018).

herramientas tecnológicas y analógicas, con el rigor académico del cual se nutre con la finalidad de fomentar, a través de una grata estadía, el aprendizaje permanente y extendido de los visitantes sobre la historia y valor patrimonial que ofrece la UNMSM.

La experiencia práctica de la propuesta ha permitido confirmar la eficacia de la implementación parcial del diseño de un centro de interpretación a tal punto que el CCSM mantiene la misma distribución, ahora con sus propios sus bienes y bajo el con- cepto básico como se expuso en la referida muestra "Academia Limensi: San Marcos en su historia”. Cabe recordar que la muestra estuvo incluida en el programa oficial por $467^{\circ}$ aniversario de fundación de la UNMSM (2018) y, además, fue una de las primeras actividades en ser inaugurada aquel año.

No obstante, la implementación de un centro de interpretación corresponde, íntegra y exclusivamente, al interés y voluntad, administrativa y política, de las autoridades universitarias, cuyas acertadas direc- 
tivas posibilitarían la creación de espacios, como el propuesto, donde la universidad pueda integrarse no sólo en los circuitos académicos ya conocidos, sino también a los dinámicos circuitos turísticos que la ciudad ofrece, hecho que involucraría, además, a los gobiernos municipales o regionales como parte de un mayor plan de desarrollo.

Es así que la acción clara y contundente de la UNMSM en el cuidado y respeto por su patrimonio histórico, a través de la implementación del diseño de un centro de interpretación, subyace en la posibilidad de crear un proceso de sensibilización, ergo, crear un sentido de identificación y valoración del patrimonio histórico universitario en favor de sus propios actores y su proyección social.

Finalmente, la implementación del diseño de un equipamiento cultural dinámico o centro de interpretación del patrimonio histórico de la Universidad Nacional Mayor de San Marcos no solo se convierte en un medio, sino también en un fin en sí mismo, cuyo trasfondo socio-histórico se enmarca, precisamente, en la relación del sujeto social con la reminiscencia histórica y cuya base fundamental recala en el criterio de la cultura como herramienta de prestigio y promoción del desarrollo.

\section{Referencias bibliográficas}

Agustín, Reinhard (2005). Origenes y evolución del cinjunto arquitectónico de la Casona de San Marcos. Lima: AECI.

Ballart, Fullola \& Petit (1996). El Valor del Patrimonio Histórico. Complutum Extra, 2015-224.

Ballart, Josep (2002). «Pasado, Historia, Patrimonio». En J. Ballart, El patrimonio histórico y arqueológico: valor y uso (págs. 29-59). Barcelona: Ariel.

Baquíjano, Josép (1791). «Historia de la Fundación, Progresos y Actual estado de la Real Universidad de Lima». Mercurio Peruano, 160-209.

Bertonatti, Claudio (2009). Los centros de visitantes y de interpretación. Buenos Aires.

Bertonatti, Iriani \& Castelli (2010). «Los centro de interpretación como herramientas de conservación y de desarrollo». Boletín de Interpretación, 21-26, Buenos Aires.

Сово, Bernabé (1956). Biblioteca de autores españoles. Obra del P. Bernabé Cobo. Madrid: Gráficas Orbe.
DÁvila, Jose (1854). Bosquejo histórico de la fundación de la insigne Universidad Mayor de San Marcos de Lima, de sus progresos y actual estado; y matrícula de los SS. que componen su muy ilustre claustro 6 de Setiembre de 1854. Lima: Imp. de Eusebio Aranda.

Dunbar, Ella (1974). La Universidad de San Marcos en el proceso de la Emancipación Peruana. Lima: CNSIP.

Eguiguren, Luis (1912). Ctálogo histórico del claustro de la Universidad de San Marcos, 1576-1800. Lima: Imprenta El Progreso.

Maticorena, Miguel (1921) Historia de la Universidad de San Marcos, hasta el 15 de julio de 1647 de Antonio de la Calancha. Transcripción. Lima: Imp. de «La Tradición».

Maticorena, Miguel (1951). Diccionario histórico-cronológico de la Universidad Real y Pontificia de San Marcos y sus Colegios. Lima: Impr. Torres Aguirre.

Maticorena, Miguel (1951). La Universidad San Marcos en el siglo XVI. Lima: Univiersidad de San Marcos.

Fuentes, Manuel (1861). Guia histórico-descriptiva. Administrativa, judicial y de domicilio de Lima. Lima: Librería Central.

Fuentes, Manuel (1866). Lima or sketches of the capital of Perú. Historical, statistical, administrative, comercial and moral. Trübner \& Co, Londres, UK.

Hobsbawm \& Terence (2003). The invention of Tradition. Cambridge University Press, Cambridge, UK.

Mariátegui, Ricardo (1951). Valiosa techumbre historiada de la Facultad de Letras de la Universidad de San Marcos. Lima: Instituto de Investigaciones de Arte Peruano y Americano.

Martín, Carolina (2009). "Los centros de interpretación: urgencia o moda”. Hermes, 50-59. Barcelona.

Maticorena, Miguel (2000). San Marcos de Lima. Universidad Decana de América. Una argumentación histórico-jurídica. Lima: Fondo Editorial UNMSM.

Maticorena, Miguel (2013). 1551. La Universidad de San Marcos de Lima. Lima: Editorial Universitaria-URP.

Maticorena, Miguel (2013). La Universidad de San Marcos de Lima. Documenta Histórica. Lima: Fondo Editorial de la UNMSM.

Peña, Mariano (1938). La fundación de la Universidad Mayor de San Marcos de Lima. Lima: UNMSM.

Pinelo, León (1648). Hypomnema apologeticum pro regali Academia Limensi in Lipsianam periodum. Lima.

Pinto-Bazurco, Ricardo (16 de abril del 2018). Carta dirigida al Director del CCSM convalidando el préstamos de bienes culturales para la exposición. Lima. 
Pinto-Bazurco, Ricardo (9 de mayo de 2019). San Fernando Informa. Boletín de la Facultad de Medicina de la UNMSM.

Porras, Raúl (1963). Fuentes históricas peruanas. Lima: IRPB-UNMSM.

Porras, Raúl (2010). San Marcos y la cultura peruana. Mito, tradición e historia del Perú. Lima: Fondo editorial UNMSM.

Porras, Raúl (2018). Fuentes históricas peruanas. Lima: Fundación M.J. Bustamante de la Puente.

PROLIMA (2016). Mapa Centro Histórico de Lima. Lima.

PROLIMA (2017). Recuperando la memoria de Lima. Lima: Tarea Asociación Gráfica Educativa.

Tamayo, Castillo, Beli, Mticorena, Chávez. (1972). El Libro y San Marcos. Catálogo. Exposición de "El Libro y San Marcos» (págs. 5-6). Lima: Editorial Jurídica S.A.

Thyssen-Bornemisza, M. N. (2019). Repensar los museos. Madrid: Fundación Colección Thyssen-Bornemisza.

Unanue, Hipólito (1793 (1985)). Guia Política, Eclesiàstica y militar del Virreynato del Perú (facsimilar). Lima: COFIDE.

UNMSM. (12 de febrero del 2018). Resolución Rectoral $N^{o}$ 00598-R-18. Lima: UNMSM.

UNMSM (23 de abril de 2018). La UNMSM inició su $467 .{ }^{\circ}$ aniversario con actividades que dieron a conocer su historia. Boletín de la UNMSM.
UNMSM (20 de marzo de 2018). UNMSM. Obtenido de http://www.unmsm.edu.pe/archivos/programa_467im.pdf

UNMSM (Mayo 2017). Exposición «Academia Limensis». San Marcos al día.

VAlCÁrCel, Carlos (1960). Reformas virreinales en San Marcos. Lima: UNMSM.

Valcárcel, Carlos (1966). El Libro XIV de Claustros de la Universidad de San Marcos. Lima: Facultad de Letras y Ciencias Humanas.

VALCÁrCel, Carlos (1974). Obra educativa de Bolivar y su recibimiento en San Marcos. Lima: Universidad Nacional Mayor de San Marcos.

VAlCÁrcel, Carlos (1950). Orden sobre los trajes de los estudiantes. Centauro No 2.

Valcárcel, Carlos (1962). San Marcos en 1788. Lima: UNMSM.

Valcárcel, Carlos (1968). San Marcos, Universidad Decana de América. Lima: UNMSM.

Villarán, Manuel. (1938). La Universidad de San Marcos de Lima. Los orígenes: 1548-1577. Lima: Librería e Imprenta Gil s.a..

Vovelle, Michael (2003). Aproximación a la Historia de la Mentalidades Colectivas. Lima: Fondo Editorial de la Facultad de CCSS-UNMSM. 